\title{
Onomatopeyas del chino moderno
}

\section{Onomatopoeia in Modern Chinese}

\author{
Qiao Yun ${ }^{1}$ \\ Universidad de Granada (España)
}

Recibido: 26-01-16

Aprobado: 13-02-16

\section{Resumen}

Este artículo estudia brevemente las onomatopeyas del chino moderno en tres grandes aspectos. El primero de ellos estudia la expresión de las onomatopeyas y el amplio rango de significados semánticos en la imitación de voces humanas, sonidos de animales o de la naturaleza y demás. La segunda, los rasgos fonológicos que presentan las onomatopeyas en sus estructuras silábicas, formas reduplicadas, consonantes, vocales, etc. La tercera estudia cómo las onomatopeyas también participan en la formación de términos, donde quedan incluidas las palabras compuestas, los verbos, los adjetivos descriptivos, los adverbios y también, entre otros casos, cómo las onomatopeyas pueden funcionar como verbos.

Palabras-clave: lexicogénesis, lexicón mental, onomatopeya, lengua china.

\footnotetext{
${ }^{1}$ (juliaqiaoyun@hotmail.com). Máster en Enseñanza del Chino como Lengua Extranjera de la Universidad de Pekín; actualmente prepara su doctorado en Lingüística General en la Universidad de Granada. Ha enseñado la lengua y la cultura de China en una amplia gama de países y centros, como por ejemplo: curso de lengua china a estudiantes internacionales en la Universidad de Pekín; curso de mandarín hablado a estudiantes de CIEE de EE.UU.; curso intermedio de lectura a los estudiantes noruegos de la Universidad de Oslo; enseñanza avanzada del idioma chino en curso on line para estudiantes japoneses de la Universidad de Waseda, etc. Ha impartido conferencias diversas en distintos eventos e instituciones académicas, como 'El instituto Confucio y la enseñanza del chino en España' conferencia impartida en el 'III Simposio internacional de actualización en tendencias y disciplinas lingüísticas', Granada, diciembre de 2015. Asimismo, como profesora visitante, ha impartido diversas conferencias en el Instituto Confucio de la Universidad de Granada desde 2010 a 2014. Sus intereses de investigación se centran en lexicón mental chino y la historiografía de los diccionarios chinos. Algunos de sus trabajos académicos son: Cultural Factors in Semantic Extension: A Typological Perspective on Chinese Polysemy, Language Design 17 (2015): 111-144; El aprendizaje y la enseñanza del vocabulario chino, en Ciruela Alférez, Juan José (Ed.), Aprender Y Enseñar Chino: Jornadas académicas sobre la lengua china y su enseñanza, 219-233, 2014, Granada: Editorial Universidad de Granada; Learn Chinese through Music “歌で学ぶ中国語” (traducción al japonés), 2009, Beijing 北京: World Publishing Corporation 世界图书出版公司.
} 


\begin{abstract}
This article briefly discusses the onomatopoeia of modern Chinese in three main aspects. The first, the onomatopoeic words express wide-ranged semantic meanings by imitating the sounds of human beings, animals, nature and so on. The second, Chinese onomatopoeia presents phonological features on their syllables, reduplicative forms, consonants and vowels, etc. The third, Chinese onomatopoeia also participates in word formation, including compounding nouns, verbs, descriptive adjectives, adverbs, etc.; conversions from onomatopoeias to verbs are also very common.
\end{abstract}

Key-words: lexicogenesis, mental lexicon, onomatopoeia, Chinese language.

\title{
0. Introducción
}

La lexicogenésis se ocupa de las dinámicas creadoras y acrecentadoras del vocabulario. El vocabulario surge y se desarrolla de muchas maneras. La manera más inmediata de creación léxica la constituyen las onomatopeyas y los ideófonos; estos pueden considerarse como elementos primarios y existen en todas las lenguas, aunque su importancia no sea igual en cada lengua. Con todo, la importancia de la onomatopeya aun en las lenguas en las que alcanza mayor relevancia resulta comparativamente poco importante comparada con otros mecanismos lexicogénicos secundarios mucho más productivos e importantes.

Se conoce como onomatopeya el recurso expresivo universal mediante el cual se crean signos que de una manera más o menos aproximada imitan o están inspirados directamente por la realidad. Un ejemplo de esto, según Ullmann $(1952,1962,1964)$, son los distintos sonidos que hacen los animales y que se reflejan más o menos directamente en todas las lenguas. Así, la palabra española cuco o la palabra inglesa cuckoo representa el grito de un pájaro que, metonímicamente, representa a dicho pájaro. En otros casos la correspondencia es más dudosa: guau-guau, quiquiriquí, etc., se corresponden con menos aproximación con las inglesas woof woof (bow wow), cock-a-doodle-doo.

De manera categórica, se podría afirmar que las onomatopeyas no son iguales en todos los idiomas, porque las distintas lenguas y culturas tienen su propia percepción auditiva y su propio sistema fonético². Además, las onomatopeyas

\footnotetext{
${ }^{2}$ Un somero análisis muestra que las onomatopeyas no juegan el mismo papel en todas las lenguas. Algunas lenguas como el inglés son ricas en onomatopeyas: clink, clang, clash, splash, splutter, spurt, crash, whistle, whirr, whizz, wheeze, giggle, sizzle, etc. El japonés tiene expresiones como wan wan para referirse al ladrido del perro, nyaanyaa para el maullido del gato, kaakaa para el graznido del cuervo, hinhin para el relincho del caballo, meemee para el balido de la cabra o la oveja, moomoo para 
en chino son sistemas muy amplios, multifuncionales y ambiguos; de ahí que la traducción palabra por palabra sea un recurso imposible de aplicar. Por este motivo, algunos estudios intentan definir un método exhaustivo y establecer una base de datos a gran escala que den explicación a las onomatopeyas chinas y a todo su campo semántico ${ }^{3}$. Meng Cong (孟琮 1983) describió la complejidad de las onomatopeyas del dialecto de Pekín tras escuchar los 402 sonidos onomatopéyicos, y los clasificó de acuerdo con su forma silábica y la reduplicación de estructuras. Ying Xuefeng (应学凤 2012) analizó las 227 entradas de onomatopeyas de la versión de 2005 del Diccionario de Chino Moderno (《现代汉语词典》, Xiàndài Hànyǔ Cídiăn) ${ }^{4}$ para estudiar las peculiaridades silábicas de las onomatopeyas en chino, y determinó que las últimas sílabas de las onomatopeyas bisílabas del chino tienen una mayor sonoridad (o al menos la misma) que justamente la sílaba anterior. Es mucho más interesante de apreciar de manera semántica la investigación de Li Jing’er (李镜儿 2007), en la que se estudió 845 onomatopeyas del chino moderno.

\section{Significados semánticos de onomatopeyas del chino moderno}

\subsection{Onomatopeya de voces humanas}

De acuerdo con el tema de estudio, Li Jing'er (李镜儿 2007) clasificó las onomatopeyas en correlativos de humanos, correlativos de animales, correlativos de la naturaleza y otros de objetos o de sonidos afines. Se ha compilado para tal estudio la siguiente tabla de descripción ${ }^{5}$ :

el mugido de la vaca, kokekokkoo para el kikirikí del gallo, piyopiyo para el piar de los pollos, kakkoo para la canción del cuco y también como denominación para el nombre de este pájaro, hoohoohoo para el sonido del búho, chinchirorin para el chirrido del grillo, kerokero para el croar de la rana, etc. Pero además de estos, como se ha indicado, el japonés tiene además centenares de expresiones onomatopéyicas para designar los fenómenos de la naturaleza, los ruidos humanos o de los diferentes oficios, los sentimientos, actitudes, enfermedades, etc.

${ }^{3}$ Véase también Rao Qin (饶勤 2000) y Ling Yun (凌云 2006).

${ }^{4}$ Beijing 北京: La Prensa Comercial 商务印书馆.

${ }^{5}$ Tabulada otra vez por el autor, superinducida la traducción de la clasificación de los objetos de estudio y pinyin etiquetado. 


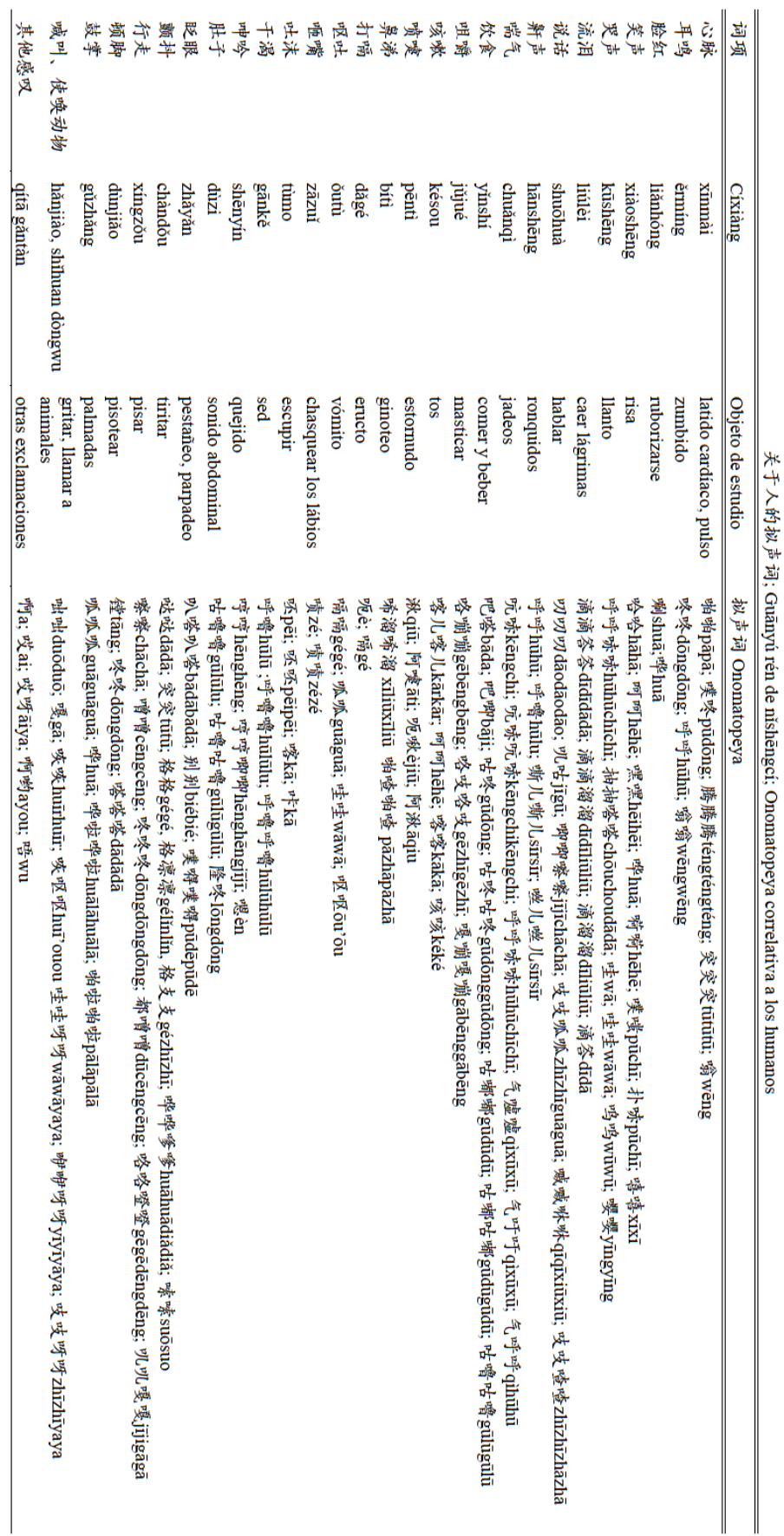


A pesar de que algunos ejemplos atípicos como 呼噜 (hūlū); 呼噜噜 (hūlūlu); 呼噜呼噜 (hūlūhūlū) que describen la sensación de tener sed, la amplia mayoría de las onomatopeyas que se han incluido en la tabla son las adecuadas para describir los correspondientes realidades, como por ejemplo el sonido de acciones o movimientos. Sin embargo, como señala Li Jing'er (李镜 儿 2007), existen unas pocas onomatopeyas que pueden usarse para actividades fisiológicas silenciosas, como por ejemplo: 脑子里嗡的一声 (năozi li wēng de yīshēng; un zumbido en el cerebro), es cierto que los cerebros no producen ningún sonido pero aquí la onomatopeya 嗡 (wēng; un zumbido, el sonido de una rápida vibración) representa un estado mental de shock. Existen muchos otros ejemplos de onomatopeyas que describen sonidos inaudibles y otras onomatopeyas que representan actividades que no producen sonido: ojos)

吧嗒吧嗒眨眼睛 (bādabāda zhă yănjing; parpadear, bādabāda-parpadear-

㗼地睁开眼睛 (pū de zhēngkāi yănjing; abrir los ojos repentinamente; pū-partícula- abrir los ojos)

哆哆嗦嗦地颤抖 (duōduosuōsuo de chàndǒu; tiritar, duōduosuōsuotemblor)

脸唰地红了 (liăn shuā de hóng le; ruborizarse, cara-shuā-partícula-rojopartícula)

Aparentemente "parpadear", "abrir los ojos", "tiritar" y "ruborizarse" no producen ningún sonido, y las onomatopeyas son más parecidas a ideófonos, es decir signos que evocan a ideas o imágenes en sonido. Las impresiones vívidas pueden ser de ciertas sensaciones o percepciones sensoriales, como por ejemplo acciones, movimientos, colores o formas. La neurociencia puede aportar algunas interpretaciones como la pseudoestesia o la sinestesia ${ }^{6}$.

\subsection{Onomatopeya de voces animales}

Los ruidos de los animales constituyen algunas de las onomatopeyas más recurrentes y más universales, como por ejemplo 汪汪 (wāngwāng; el ladrido de los perros), 喵喵 (miāomiāo; el maullido de los gatos), 哼哼 (hēnghēng, el gruñido de los cerdos), 哞哞 (mōumōu; el mugido de reses menores), 咩咩 (miēmiē; el balido de cabras u ovejas), 咴咴 (huīrhuīr; el relinche de caballos o mulas), 得得 (dédé; el ruído de golpe de cascos de caballos contra el suelo), 吹吹喳喳 (jījichācha; el gorjeo de pájaros o chicas), 咕咕 (gūgū; el arrullo de

\footnotetext{
${ }^{6} \mathrm{La}$ seudoestesia o sinestesia, de forma general, es un fenómeno neurológico en el que la interpretación relativa a un sentido o parte del cuerpo se produce por el estímulo de otro sentido o parte del cuerpo.
}

Araucaria. Revista Iberoamericana de Filosofía, Politica y Humanidades, año 18, $\mathrm{n}^{\circ} 35$. Primer semestre de 2016. Pp. 217-229. ISSN 1575-6823 e-ISSN 2340-2199 doi: 10.12795/araucaria.2016.i35.11 
palomas), 扑棱棱 (pūlēnglēng, el sonido del batir de alas de pájaros), 啾啾 (jiūjiū, el trinar de pájaros o insectos), 嘎嘎 (gāgā; el graznido de patos u ocas), 呱呱 (guāguā; el croar de ranas) ${ }^{7}$, 吱吱 (zhīzhī; el chillido de los ratones), 嘶 嘶 (sīsī; el siseo de la serpiente), 嗷鸣 (áowu, el aullido de los lobos), 吼 (hǒu, el rugido del león o bestias), etc.

Aunque las onomatopeyas de las voces de los animales son abundantes, existes muchos verbos compuestos con el verbo hiperónimo 叫 (jiào; grito de animal), entre los hipónimos compuestos tenemos: 吠 (fèi, ladrido de un perro), 吠叫 (fèijiào; ladrido de perro), 吼 (hǒu; rugido, de bestias o de viento), 吼 叫 (hǒujiào; de bestias o de viento), 嚎 (háo; gruñido de bestia y humano), 嗥 (háo; aullido de lobo), 嚎叫 (háojiào, gruñido de bestia o humano), 跘叫 (háojiào; aullido de bestia), 咆哮 (páoxiāo; rugido de bestia o humano), 鸣 (míng; canto de pájaros o replique campanas), 鸣叫 (míngjiào; el canto o el graznido de pájaros), 啼 (tí; graznido de pájaros), 啼鸣 (tímíng, graznido de pájaros). Muchos animales no tienen ningún verbo específico para representar su voz y usan el término general 叫 (jiào, grito de animal) como por ejemplo los gatos, cerdos, reses bovinas, burros. Exiten palabras como 乌啼 (wūtí; graznido de cuervo), 虎啸猿啼 (hǔxiàoyuántí; el rugido del tigre o la voz del mono), 鹤唳 (hèlì; la voz de la grulla), 虫嘶 (chóngsī; el siseo de insectos), 马 嘶 (măsī; el relincho) que se usan en muchas ocasiones como sustantivos en el registro literario.

\subsection{Onomatopeyas de sonidos de la naturaleza y de otros objetos}

Las onomatopeyas provienen de fenómenos naturales, movimiento de objetos, cambios de estado y también de otros sonidos abióticos, como por ejemplo: 哗啦啦 (huālālā; el sonido del golpe de la lluvia, agua corriendo o caída de grava, etc.), 淅淅沥沥 (xīxīlilì̀; el golpeteo de las gotas de lluvia), 籁 籁 (sùsù; el sonido del corte de tijeras o del crujido de las hojas), 密窣 (xīsū; el crujido de tela o de hojas), 謏獀 (sōusōu; el zumbido del viento), 呼呼 (hūhū; el sonido del viento o del fuego, el resuello de la respiración), 瑟瑟 (sèsè; el susurro de las hojas o del viento), 轰隆隆 (hōnglónglóng, truenos, el sonido de máquinas o de armas de fuego), 咔嚓 (kāchā; el sonido del chasquido de partes

\footnotetext{
${ }^{7}$ Las onomatopeyas 呱呱叫 (guāguājiào; guāguā-llanto, llamada o voz) o 顶呱呱 (dǐngguāguā; parte superior-guāguā) significan "fantástico", “muy bien”. Wang Guanghan (王光汉 2010) verificó que ambas palabras derivan de adjetivos del dialecto Wu 刮刮叫 (guāguājiào) y 顶刮刮 (dǐngguāguā) y que el componente 刮 (guā) significa "prensado o planchado de forma excelente", se puede entender que el sentido extendido de "bueno, excelente", y crear a partir de él más formas a partir de reduplicaciones y de fonogramas. De ahí, se produce el siguiente juego de palabras con ambas ideas 赶鸭子上架——呱呱叫 (găn yāzi shàng jià: guāguājiào; cuya primera parte significa de traducción literal es conducir a un pato hacia un lugar elevado, que se trata de una fase idiomática o modismo que significa empujar a alguien a hacer algo que está por encima de sus posibilidades; y la segunda es genial).
}

Araucaria. Revista Iberoamericana de Filosofia, Política y Humanidades, año 18, nº 35. Primer semestre de 2016. Pp. 217-229. ISSN 1575-6823 e-ISSN 2340-2199 doi: 10.12795/araucaria.2016.i35.11 
de máquinas o de algunas fracturas $)^{8}$, 噼啪 (pīpā; el chasquido de las chispas), 哔哔剥剥 (bìbìbōbō; el sonido de la leña ardiendo), 潺潺 (chánchán, el sonido del agua corriendo), 洰洰 (gǔgǔ; el borboteo de los manantiales de agua), 哗 哗 (huālālā; el silbido de la lluvia o del agua corriendo), 嘀嘀嘀 (dīdīè̄; el pitido de una bocina o de un timbre), 叭叭 (bābā, el sonido de los labios, de una bofetada, o de hablar), 笃笃 (dǔdǔ; el sonido de patear o de llamar a la puerta), 咚咚咚 (dōngdōngdōng; el sonido de los tambores, llamar a la puerta, etc.), 叮 叮当当 (dīngdīngdāngdāng; el tintineo de objetos metálicos), 咯吱 (gēzhī; el chirrido de una tarima o al abrir una puerta), 哐当 (kuāngdāng; el sonido fuerte de un disparo o de una puerta cerrándose), 嚓嚓 (chāchā; el sonido que se produce al cortar con una guadaña), 哧溜 (chīliū; el sonido del deslizamiento), 咕噜噜 (gūlūlū; borborigmo, vibración), 㗼通 (pūtōng; el sonido de algo cayendo en agua), 镊铭 (kēngqiāng, voces sonoras, el sonido del jade o metales y otros instrumentos musicales).

De este modo las onomatopeyas pueden expresar diferentes sonidos y muchas onomatopeyas pueden describir las mismas o parecidas voces, como por ejemplo 呱呱 (guāguā) puede hacer referencia a las voces de los patos o de las ranas, y tanto 嘤嘤 (yīngyīng) como 抽抽嗒嗒 (chōuchōudādā) indican el sonido de sollozos. Para los sonidos abióticos, las onomatopeyas no siempre son suficientemente específicas, y en muchos fenómenos son insuficientes, como ha quedado demostrado con los ejemplos ya expuestos. Por esta razón se hace indispensable incluir la designación del objeto al que se hace referencia, como 轰隆隆的炮声 (hōnglónglóng de pàoshēng; el rugido de las pistolas), 轰隆隆 的雷声 (hōnglónglóng de léishēng; truenos) y 轰隆隆的马达声 (hōnglónglóng de mădáshēng; el rugido de los motores). Sin embargo, en algunos casos existen algunas colocaciones estandarizadas; por ejemplo 锒铛 (lángdāng; el choque de objetos metálicos) se usa para 银铛入狱 (lángdāngrùyù; encadenar y encarcelar) representa "el entrechocar de las cadenas", pero no se usa como onomatopeya para representar otros tipos de choques de metales.

La ambigüedad y la indefinición de las onomatopeyas también se muestran en la forma en la que aparecen escritas. Muchas onomatopeyas presentan distintas grafías en caracteres chinos, como 叮当 (dīngdāng; el tintineo del jade, de la porcelana o de objetos metálicos), que puede aprecer también como 丁当 (dīngdāng) y 玎珰 (dīngdāng); o 噗通 (pūtōng; el ruido de la caída de un objeto en agua) y 扑通 (pūtōng) ${ }^{9}$. Este hecho puede atribuirse a que los caracteres sínicos son más ideográficos que fonográficos. Y a que además los componentes ideográficos de los caracteres chinos pueden determinar la

\footnotetext{
${ }^{8}$ La palabra onomatopéyica 咔嚓 (kāchā; el sonido del chasquido de partes de máquinas o de algunas fracturas) de manera informal se refiere a sentidos verbales tales como "cortar una cabeza", "ir en contra de la opinión de alguien", "rechazar un plan", etc.

${ }^{9}$ A pesar de que 嘤嘤 (yīngyīng) se centra en un llanto continuo, la onomatopeya 抽抽嗒嗒 (chōuchōudādā) enfatiza en el mismo sonido intermitente.
} 
selección de las variantes. Por ejemplo, 玎珰 (dīngdāng; el tintineo del jade, de la porcelana o de objetos metálicos) es más apropiado para el sonido del jade que en 环佩玎珰 (huánpèidīngdāng; el tintineo de piezas de jade que se llevan encima), por el radical del carácter que lleva 王 (wáng; jade). Otro ejemplo, la onomatopeya 謏㥰 (sōusōu; el zumbido del viento) hace referencia expresamente al viento ya que usa el radical 风 (fēng; viento) mientras que 嗖 嗖 (sōusōu; sonido silbante) se usa generalmente para sonidos de movimientos ligeros y rápidos.

Además de las onomatopeyas que describen procesos fisiológicos silenciosos, podemos encontrar ejemplos de otros fenómenos naturales, como es el caso de la expresión: 时间嗖嗖嗿地飞逝 (shíjiān sōusōusōu de fēishì, el tiempo vuela como una flecha, el tiempo pasa rápidamente ['tiemposōusōusōu-PARTÍCULA-vuela’, aquí la onomatopeya 嗖嗖嗖 representa un sonido sibilante, un sonido de roce]).

\section{Rasgos fonológicos de las onomatopeyas del chino moderno}

Las onomatopeyas de la lengua china tienen varios patrones de sílabas, que pueden ser del orden de monosílabos, bisílabos, trisílabos e incluso cuadrisílabos, pero son raras las onomatopeyas de cinco sílabas o más. Muchas onomatopeyas son polisílabas porque han sido reduplicadas, es decir, poseen una forma básica del mismo significado, por ejemplo, 喵 (miāo; miau) y 喵 喵 (miāomiāo; miau), 咕噜 (gūlū; borborigmo, ronroneo o retumbo) y 咕噜噜 (gūlūlū; borborigmo, retumbo), 咚 (dōng; el sonido del tambor, o el de llamar a la puerta, etc.) y 咚咚咚 (dōngdōngdōng; tamborileo, el sonido del tambor, o el de llamar a la puerta, etc.); 淅励 (xîlì; el golpeteo de las gotas de lluvia, el sonido de la brisa o de hojas cayendo) y 淅淅沥沥 (xīxīlìlì; el golpeteo de las gotas de lluvia). Sin embargo, algunas onomatopeyas polisílabas no poseen una forma base, o lo que es más, las sílabas relevantes pero de diferente longitud no representan los mismos sonidos. En el siguiente ejemplo: 嘤 (yīng; el sonido de los pájaros) cambia su significado cuando se reduplica 嘤嘤 (yīngyīng; el apenas audible sonido de un llanto continuo); 吹里咕噜 (jīligūlū; el sonido indistinguible y apenas inteligible de personas hablando; retumbo) es otro en lugar de 吹咕 (jīgū; el sonido de hablar en voz baja), 咕噜 (gūlū, borborigmo, ronroneo, retumbo) y 咕吹 (gūjīi; el chapoteo del fango cuando se camina sobre él, el sonido de hablar en voz baja o el de hablar solo para sí mismo en voz baja). Wang Hongjun (王洪君 1996) observó que las lenguas con una estructura de sílabas simple tienden a tener más onomatopeyas con una estructura bien definida, mientras que las lenguas con una estructura de sílabas más compleja poseen un conjunto de estructuras de onomatopeyas con menos excepciones. El 
chino tiende a ser del primer grupo. Las diversas formas de reduplicación y la flexibilidad del número de sílabas son algo evidente en la lengua china.

Además del número de sílabas y de las formas reduplicadas, las onomatopeyas chinas tienen rasgos fonológicos en sus consonantes y vocales. $\mathrm{Li}$ Jing'er (李镜儿 2007) descubrió que no hay onomatopeyas que comiencen por /f/ o /r/. Shao Jingmin (邵敬敏 1981) observó que las sílabas de onomatopeyas que comienzan por "l" sólo podían colocarse en la última sílaba, como en el ejemplo 吹里咕噜 (jīligūlū; el sonido indistinguible y apenas ininteligible de personas hablando, retumbo). Meng Cong (孟琮 1983) concluyó que de forma estadística los fonemas $/ 1 /, / \mathrm{m} / \mathrm{y} / \mathrm{n} /$ apenas aparecen en las formas silábicas de las onomatopeyas chinas; y si dos sílabas comparten la misma consonante inicial, la vocal de la primera sílaba podría ser una vocal cerrada como la /i/ y la última sílaba podría ser una vocal abierta como la /a/; en el caso de que haya codas de sílabas, ambas sílabas compartirán la misma terminación consonántica. Un ejemplo podría ser 滴答 (dīdā; goteo), y 玎珰 (dīngdāng; el tintineo del jade, la porcelana u objetos metálicos). Además, Ying Xuefeng (应 学凤 2012) notó que la última sílaba de las onomatopeyas bisílabas pueden ser más largas que la primera, y además tónica, como en 扑棱 (pūlēng; el sonido del batir de alas de pájaros), 哧溜 (chīliū; el sonido del deslizamiento), 嘎嘣 (gābēng; el sonido de masticar) y 噗通 (pūtōng, el sonido de un objeto al caer al agua). Sin embargo, las conclusiones están abiertas al debate debido a las numerosas excepciones que podrían citarse, tales como: 哐当 (kuāngdāng; el sonido fuerte de un disparo o de una puerta cerrándose) y 吭哧 (kēngchī; soplido) cuya última sílaba es más larga que la anterior.

Otra característica fonológica de las onomatopeyas del chino, además de la caracterización según la estructura silábica, es que un gran número de ellas son palabras bisilábicas continuas e inseparables, conocidas en inglés como Lianmian-words (联绵词, liánmiáncí), que son o aliteraciones (en chino 双 声, shuāngshēng) o rimas (en chino 叠韵, diéyùn). Veamos algunas de las onomatopeyas con aliteraciones: 叮当 (dīngdāng; el tintineo del jade, la porcelana u objetos metálicos), 叮咚 (dīngdōng; el sonido del goteo, el tintineo del jade u objetos metálicos), 唏嘘 (xīxū, suspiro), 噼啪 (pīpā; el chasquido de las chispas del fuego), 乒乓 (pīngpāng; el sonido del ping pong), etc. Otros ejemplos de onomatopeyas que riman son: 咔嚓 (kāchā; el sonido del chasquido de partes de máquinas o de algunas fracturas), 锃铭 (kēngqiāng; voz sonora de una persona, el sonido del jade o metales y otros instrumentos musicales), 银 铛 (lángdāng; el choque de objetos metálicos), 淅沥 (xīlì; el golpeteo de las gotas de lluvia, el sonido de la brisa o de hojas cayendo), 轰隆 (hōnglóng; truenos, el sonido de máquinas o de armas de fuego), 咕嘟 (gūdū; burbujear, sonido de tragar), 哐啷 (kuānglāng; bang, exploxión), 唼喋 (shàzhá, el sonido de los peces o de peces acuáticos tragando) y otras más. Las onomatopeyas 
polisílabas incluso tienen su propio tipo de aliteración o de una aproximación a la aliteración acompañada de una rima o de una rima aparente, como 嘀里 嘟噜 (dīlidūlū, parloteo), 吹里喳啦 (jīlizhālā, un ruido no identificable, voces humanas, ruidos de pájaros, etc.), 噼里啪啦 (pīlipālā, chasquido), etc. En realidad, las características estéticas y fonológicas actuales de las onomatopeyas son resultado de la evolución de la lengua. Wang Li (王力 1957) afirma que las onomatopeyas monosílabas y las formas reduplicadas eran más frecuentes en el periodo previo a la Dinastía Qin, pero no las aliteraciones (双声, shuāngshēng) ni las rimas (叠韵, diéyùn). El paralelismo y lo ornamentado de la literatura promovió las propiedades del discurso oral.

Se han detectado algunas conexiones entre los sonidos y sus significados en las onomatopeyas, tanto en chino como en otras lenguas. Las consonantes de manera específica pueden mostrar las relaciones naturales en cierta medida, por ejemplo, la /b/ y la /p/ están relacionadas con un estallido, la /1/ está relacionada con "el deslizamiento", la /k/ implica "rotura", la /c/ y la /s/ denotan fricción, la /d/ y la combinación de consonantes final /ng [n]/ implican impacto, etc. Cierto es que dichas conexiones no puede afirmarse que sean del todo precisas, pero sí que sean razonadamente universales.

\section{Formación de palabras a partir de onomatopeyas del chino moderno}

Las onomatopeyas chinas no solo representan sonidos, sino que también formas fonéticas nominales, verbales, adjetivales, adverbiales, etc., tal y como lo hace el origen del término, que proviene del latín, que a su vez viene del griego, que significa "acuñar una palabra en imitación a un sonido".

Los filólogos de chino histórico tienen la tradición de establecer la raíz de la nominalización léxica en los símbolos fonológicos. Está muy extendida la idea de que la nomenclatura - nombres de ciertos animales provienen de sus voces, como por ejemplo 猫 (māo, gato), 鸭 (yā, pato), 我 (é, oca), 鸽 (gē, paloma), 鹊 (què, urraca), 蛙 (wā, rana) ${ }^{10}$ y demás. Existen más ejemplos sustanciales en el chino moderno entre los que se incluye 蝈蝈儿 (guōguōr; saltamontes longicornios), 蛐蛐儿 (qūqūr; grillo, 知了 (zhīliăo; cigarra), y 咪咪 (mīmī; miau, gato) que claramente provienen de sus voces. Otras como 布谷 (bùgŭ; cuco), 乒兵 (pīngpāng, ping-pong), 银铛 (lángdāng; el choque de objetos metálicos, encadenar y encarcelar), etc., que sugieren que las onomatopeyas pueden aplicarse a los objetos o seres relacionados con tales ruidos.

Además, algunos elementos de las onomatopeyas sirven también como morfemas para crear nombres compuestos, como 布谷鸟 (bùgǔniăo; cuco, pájaro), 哈巴狗 (hăbagǒu; pug [perro de nariz chata], que surge de la onomatopeya de perro), 叭儿狗 (bārgǒu; perro pekinés, que surge de la onomatopeya de perro), 乒

${ }^{10}$ Véase 《现代汉语词典》(Xiàndài Hànyǔ Cídiăn, Mordern Chinese Dictionary), Página 318, 1062. 
乓球 (pīngpāngqiú, tenis de mesa, onomatopeya-pelota), 铛铛车 (dāngdāngchē; carrito, que surge de la onomatopeya del vehículo), 蹦蹦车 (bèngbèngchē; triciclo eléctrico, que surge de la onomatopeya de vehículo), 哈哈镜 (hāhājìng; espejo distorsionador de la imagen, que a su vez provoca la risa, haha), 拨浪鼓 (bōlanggǔ; tambor doble japonés, que surge de la onomatopeya de tambor), 趿 拉板儿 (tālabănr; zuecos, zapatillas de madera, [onomatopeya + tabla + SUFIJO DIMINUTIVO]), etc. El rasgo morfológico de estos sustantivos compuestos surgen de: "componente onomatopéyico + término genérico".

La nomenclatura de algunas actividades fisiológicas también presentan sonidos que se plasman en las onomatopeyas, por ejemplo 哈欠 (hāqian; bostezo), 喷德 (pēntì; estornudo), 咳嗽 (késòu; tos), 哆嗦 (duōsuo; escalofrío), 呼噜 (hūlu; ronquido), 踉趹 (liàngqiàng, tambaleo), 嗝 (gé; hipo), etc. ${ }^{11}$. Algunos no son solo sustantivos, sino que también pueden ser verbos, como 咳嗽 (késòu; toser), 哆 嗦 (duōsuo; tener escalofríos), 踉距 (liàngqiàng; tambalearse). Otras formas pueden surgir también de compuestos verbales o frases, como 打哈欠 (dǎhāqian; bostezar, que surge del ruido que se hace en esta acción), 打呼噜 (dăhūlu; roncar, gruñir), 打喷德 (dăpēntì; estornudar), 打哆嗦 (dă duōsuo; tiritar), 打嗝 (dăgé; eructar), 打哈哈 (dăhāha; jactarse, reírse), 打踉跄 (dă liàngqiàng; tambalearse) y muchas más, en los que 打 (dă; hacer una actividad fisiológica) es el constituyente característico que construye junto a un significado verbal indefinido.

Aparte de actividades fisiológicas, algunos otros elementos onomatopéyicos sirven también como morfemas para la composición de verbos, por ejemplo: 哄笑 (hōngxiào; carcajearse, que surge de la onomatopeya de risa), 哄抢 (hōngqiăng; desvalijar de forma pública bienes del estado, que surge de la onomatopeya de saquear), 轰鸣 (hōngmíng; fragor, estruendo de máquinas, etc.), 呼啸 (hūxiào; silbido), 哗变 (huábiàn; ruido de amotinados), etc.

La mayor parte de las onomatopeyas en la lengua china no pueden funcionar sintácticamente como un predicado; sin embargo algunos bisílabos gráficamente convertidos en verbos sí lo hacen: 滴答 (dīdā; el sonido del goteo) $\leftrightarrow$ 滴答 (dīda, gotear), 扑棱 (pūlēng, el sonido del batir de alas de pájaros) ↔ 扑棱 (pūleng; agitar algo como si fuese un ala), 吧嗒 (bādā;click) ↔吧嗒 (bāda, chasquear los labios), 吧唧 (bājīi; chapotear) ↔ 吧唧 (bāji; chasquear los labios), 咕嘟 (gūdū; burbujear) $\leftrightarrow$ 咕嘟 (gūdu; hervir mucho tiempo), 哼唧 (hēngjī, farfullar) $\leftrightarrow$ 哼 唧 (hēngji, hacer sonidos inaudibles), 嘟囔 (dūnāng; farfullar) ↔嘟囔 (dūnang; murmurar para uno mismo), 咔嚓 (kāchā, el sonido del chasquido de partes de máquinas o de algunas fracturas) $\leftrightarrow$ 咔嚓 (kācha, el sonido de cortar una cabeza o de un rechazo) $)^{12}$. Estos bisílados funcionan como onomatopeyas si la segunda sílaba pasa a ser tónica mientras que funcionan como verbos si la última sílaba pierde su tono original y toman un tono neutro.

${ }^{11} \mathrm{El}$ texto original rezaba: 音节结构简单的语言倾向于用较多的音节构造特殊的语音词, 音 节结构复杂的语言倾向于用较少的音节构造特殊的语音词的趋势则比较明显。

${ }^{12}$ Dado que "ejecutar" es en cierto modo algo tabú.

Araucaria. Revista Iberoamericana de Filosofía, Política y Humanidades, año 18, nº 35. Primer semestre de 2016. Pp. 217-229. ISSN 1575-6823 e-ISSN 2340-2199 doi: 10.12795/araucaria.2016.i35.11 
Los elementos constituyentes de las onomatopeyas pueden servir como morfemas para crear adjetivos descriptivos en sintaxis (状态词 zhuàngtàicí) ${ }^{13}$, como por ejemplo: 叭叭 (bābā; locuaz), 喷香 (pènxiāng; delicioso, aromático, que surge de la onomatopeya de sabroso, aromático), 嘎嘣脆 (gābēngcuì; crujiente, que surge de la onomatopeya de crujir), 滴溜圆 (dīliūyuán; redondo, formando por una onomatopeya y el adjetivo redondo), 梆梆硬 (bāngbāngyìng; duro, rígido, formando por una onomatopeya y el adjetivo duro), 笑嘻嘻 (xiàoxīxī; sonriente,formado por el verbo sonreir y una onomatopeya), 乐呵 呵 (lèhēhē; alegre, formado por el adjetivo alegre y una onomatopeya), 响当当 (xiăngdāngdāng; alto, ruidoso, espectacular, famoso, formado por el sustantivo sonido y una onomatopeya), 闹哄哄 (nàohōnghōng; clamoroso, ruidoso, formado por el adjetivo ruido y una onomatopeya), 甜滋滋 (tián zi zị; agradablemente dulce, formado por el adjetivo dulce y una onomatopeya), 凉謏飕 (liángsōusōu; fresco, formado por el adjetivo fresco y una onomatopeya), 热呼呼 (rèhūhū; caliente, cálido, formado por el adjetivo caliente y una onomatopeya), 唯唯诺诺 (wěiwěinuònuò; obediente, servil, formado por dos onomatopeyas).

Asimismo, los elementos formantes de las onomatopeyas pueden estar compuestos por adverbios con un cuasi sufijo -然 (-rán; -estado) por ejemplo: 戛然 (jiárán; sonido abrupto de algo que se detiene, alto y claro), 嘎然 (gārán; nítidamente y claro), 轰然 (hōngrán; ruidosamente), 怦然 (pēng rán; choque repentino), 哗然 (huárán; alboroto), 哄然 (hōngrán; bulliciosamente), 喟 然 (kuirán; suspiro), 嗒然 (tàrán; con desánimo), 铮铮然 (zhēngzhēngrán; firmemente, categóricamente).

${ }^{13}$ Véase también Guo Rui (郭锐 2002). 


\section{Referencias bibliográficas:}

Guo Rui (郭锐 2002), Un estudio de las partes de la oración del chino moderno “现代汉语词类研究”, Beijing 北京: La Prensa Comercial 商务印书馆.

Li Jing'er (李镜儿 2007), Un estudio sobre la onomatopeya del chino moderno “现代汉语拟声词研究”, Shanghai 上海: Prensa Xuelin 学林出版社.

Ling Yun (凌云 2006), Una descripción estática de la onomatopeya en el chino moderno “现代汉语拟声词系统的静态描写”, Enseñanza del Lenguaje y Estudios Lingüísticos “语言教学与研究” 6: 19-23.

Meng Cong (孟琮 1983), Palabras onomatopéyicas en el dialecto de Pekín “北京话的拟声词”, en Lü Shuxiang (吕叔湘) (Ed.) Investigaciones y Exploraciones Gramáticales (volumen I) “语法研究和探索(第1辑)”, Beijing 北京: Ediciones de la Universidad de Pekín 北京大学出版社.

Rao Qin (饶勤 2000), Una revisión de los estudios de las onomatopeyas en chino moderno “现代汉语拟声词研究综述”, Revista de la Escuela Normal de Pekín “首都师范大学学报” S3: 39-45.

Shao Jingmin (邵敬敏 1981), Una breve discusión sobre palabras onomatopéyicas “拟声词初探”, Enseñanza del Lenguaje y Estudios Lingüísticos “语言教学与研究” 4: 57-66.

Ullmann, S. (1952), Introducción a la semántica francesa, Madrid: CSIC.

Ullmann, S. (1962), Semántica: introducción a la ciencia del significado, Madrid: Aguilar.

Ullmann, S. (1964), Lenguaje y estilo, Madrid: Aguilar.

Wang Guanghan (王光汉 2010), Un estudio sobre cuestiones lexicográficas “词典问题研究”, Hefei 合肥: Ediciones de la Universidad de Anhui 安 徽大学出版社.

Wang Hongjun (王洪君 1996), Formas de Prosodia de las onomatopeyas chinas “汉语语音词的韵律类型”, Zhongguo Yuwen “中国语文” 3: 167171.

Wang Li (王力 1957), Manuscritos de la Historia del Idioma Chino (volumen I) “汉语史稿(上册)”, Beijing 北京: Editorial Científica 科学出版社. Edición Revisada de 2004, Beijing 北京: Editorial Zhonghua 中华书局.

Ying Xuefeng (应学风 2012), Características Sonoras de las onomatopeyas en chino moderno “现代汉语拟声词的后重格局”, Lingüística china “汉 语学报” 3: 77-86. 
